DOI: https://doi.org/10.24867/07HZ02Jakovljevic

\title{
OCENJIVANJE UTICAJA ŽIVOTNOG CIKLUSA MIKROTALASNE PEĆNICE NA RADNIKE
}

\section{ASSESSMENT OF MICROWAVE OVEN'S LIFE CYCLE IMPACTS ON THE WORKERS}

\author{
Marina Jakovljević, Boris Agarski, Fakultet tehničkih nauka, Novi Sad
}

\section{Oblast - INŽENJERSTVO ZAŠTITE NA RADU}

Kratak sadržaj - Istraživanje u okviru rada realizovano je $u$ tri celine. Prvi deo pruža teoretske osnove ocenjivanja životnog ciklusa sa aspekta socijalnih uticaja, kao i metodu za ocenjivanje uticaja životnog ciklusa na radnika (WELCA). U drugom delu rada primenjena je WE-LCA metoda, kako bi se procenili uticaji životnog ciklusa mikrotalasne pećnice na radnike. Dobijeni rezultati prikazani su tabelarno i grafički $i$ ukazuju na verovatnoću nastanka fatalnih povreda, raka, psiho-socijalnih oboljenja, poremećaja funkcije centralnog nervog sistema, oboljenja sluha, alergenih i nealergenih oboljenja disajnih puteva, kožnih oboljenja, oboljenja vezanih za skeletnu muskulaturu i mišiće i ostalih povreda.

Ključne reči: Radno okruženje, WE-LCA metoda, Ocenjivanje životnog ciklusa.

Abstract - Research within the paper was realized in three parts. The first part provides the theoretical foundations of Social Life Cycle Assessment, as well as a method for assessing the impact of the life cycle on the workers (WE-LCA). In the second part WE-LCA method was applied to assess the life cycle impacts of microwaves on workers. The obtained results are presented in tabular and graphical form and showed a probability of occurrence of fatal accidents, cancer, psycho-social diseases, central nervous system function disorder, hearing damages, allergic and non-allergic airway diseases, skin diseases, muscolo-sceletal disorders and other accidents.

Keywords: Working environment, WE-LCA method, Life cycle assessment.

\section{UVOD}

Ocenjivanje životnog ciklusa (engl. Life Cycle Assessment, $L C A$ ) do sada je, uglavnom, korišćeno kako bi se analizirali efekti proizvoda ili procesa na životnu sredinu.

Sve faze životnog ciklusa proizvoda su obuhvaćene, od iskopavanja i ekstrahovanja sirovina, preko transporta, pa sve do odlaganja [1]. Činjenica da će neki od proizvoda imati socijalne $\mathrm{i}$ socio-ekonomske posledice, ne samo na radnike koji učestvuju u procesu proizvodnje, već i na čitave države u kojima se proizvodnja odvija, dovodi do metode kojom se ocenjuju socijalni aspekti životnog ciklusa proizvoda (engl. Social Life Cycle Assessment, SLCA).

\section{NAPOMENA:}

Ovaj rad proistekao je iz master rada čiji mentor je bio dr Boris Agarski, docent.
Uključujući radnu sredinu prilikom ocenjivanja životnog ciklusa (engl. Working Environment Life Cycle Assessment, WE-LCA) postoji mogućnost da se utvrde potencijalne posledice radnog okruženja iz raznih proizvodnih procesa i drugih aktivnosti.

Cilj rada je da se istraže mogućnosti ocenjivanja životnog ciklusa sa aspekta uticaja na radno okruženje, odnosno, da se obrati pažnja na socijalne aspekte kao što je bezbednost i zdravlje zaposlenih, koji proizvodnjom mikrotalasnih pećnica mogu biti narušeni. U skladu sa postavljenim ciljem, zadaci rada su da se nakon uvodnih razmatranja, opišu S-LCA i WE-LCA metoda i da se životni ciklus mikrotalasne pećnice analizira WE-LCA metodom.

\section{OPIS S-LCA}

Vođenjem debata o korporativnoj društvenoj odgovornosti (engl. Corporate Social Responsibility, CSR), tokom poslednje dve decenije, javljala se sve veća potreba za usmeravanjem i savetovanjem organizacija. Eksperti za ocenjivanje životnog ciklusa 2006. godine prepoznali su potrebu da ponude prvi međunarodni dokument neobavezujućih smernica za ocenjivanje socijalnih aspekata tokom životnog ciklusa proizvoda, koji predviđa analizu i opis trenutnog sprovođenja S-LCA i predlaže kategorije socijalnih uticaja, povezanih sa ključnim interesnim grupama (zainteresovanim stranama, engl. stakeholders). S-LCA je tehnika koja ima za cilj da oceni socijalne i socio-ekonomske aspekte životnog ciklusa proizvoda, kao i ocenjivanje potencijalnih pozitivnih i negativnih uticaja tokom životnog ciklusa proizvoda, obuhvatajući sve faze: vađenje i preradu sirovina, proizvodnju, distribuciju, upotrebu, ponovno korišćenje, održavanje, reciklažu i odlaganje [1].

\subsection{Tehnike i alati za S-LCA}

Standardi predstavljaju neophodan alat mnogih industrija i državnih institucija prilikom procene uticaja proizvoda, tehnoloških procesa i razvoja propisa i zakona od značaja za zaštitu životne sredine. LCA je metoda koja je uređena međunarodnim standardima ISO 14040 i ISO14044. Kada god je to moguće, S-LCA prati okvire pomenutih standarda. Standardom ISO 14040 obuhvaćeni su principi i okvir studije LCA i studije ocenjivanja uticaja životnog ciklusa (engl. Life Cycle Impact Assessment, LCIA). Nameravana primena rezultata LCA i LCIA se razmatra tokom definisanja cilja, predmeta i područja primene. Standardom ISO14044 utvrđuju se zahtevi i obezbeđuju uputstva za primenu LCA, obuhvatajući, pored ostalog i: definicije cilja i predmeta i područja primene LCA, fazu LCIA i fazu interpretacije životnog ciklusa. 
Odgovor na pitanje čemu zapravo služe informacije koje proizilaze iz studija, dovodi nas do koncepta društveno odgovornog poslovanja (CSR). Trenutne definicije i teorije CSR smatraju da kompanije prilikom donošenja korporativnih odluka trebaju da se, u najmanju ruku, pridržavaju međunarodnih standarda ljudskih i radnih prava.

Krajnji cilj sprovođenja S-LCA jeste da podstakne poboljšanje socijalnih i socio-ekonomskih karakteristika proizvoda tokom životnog ciklusa. U poglavlju koje sledi biće razmatrana LCA radne sredine (WE-LCA).

\section{OPIS WE-LCA}

Pitanja radne sredine se obično nisu ocenjivala detaljno putem LCA, jer je fokus tehnike bio takav da se na prvom mestu ocene potencijalni uticaji na životnu sredinu. U proteklom periodu nekoliko grupa radilo je na tome da se pitanja radne sredine integrišu u LCA.

WE-LCA se koristi kako bi se ispitao uticaj životnog ciklusa na radnike, primenom podataka iz baze inventara koji su utvrđeni za veliki broj proizvodnih procesa. Metoda je bazirana na statistici povreda i oboljenja na radu u Danskoj, koja važi za jednu od vodećih zemalja ekološke proizvodnje. Prilikom ocenjivanja uticaja radnog okruženja na bezbednost i zdravlje radnika razmatraju se sledeće povrede i oboljenja:

- fatalna povreda (nesreća, udes),

- ostale povrede,

- poremećaj centralnog nervnog sistema (CNS),

- oštećenja sluha,

- rak,

- mišićno-skeletni poremećaj,

- disajni poremećaj (alergeni),

- disajni poremećaj (nealergeni),

- kožna oboljenja,

- psiho-socijalni poremećaj [2].

Razvijeno je nekoliko metoda WE-LCA koje omogućavaju da se ispita da li su poboljšanja proizvoda, u cilju zaštite životne sredine, sprovedena na račun pogoršanja radnog okruženja.

\subsection{WE-LCA metode}

Metode WE-LCA imaju za cilj da sakupe i ocene potencijalne uticaje radne sredine na ljudska bića tokom životnog ciklusa proizvodnog sistema. Pregledne (engl. screening) metode se koriste da ukažu na značajne oblasti u životnom ciklusu proizvoda, prvenstveno kako bi se procenilo da li su potrebne dodatne studije.

Sektor metode se odnose na probleme radne sredine specifičnih delatnosti, obično sektora, a koriste statističke podatke iz nacionalnih baza podataka, kao što su podaci dobijeni anketnim ispitivanjem stanovništva.

Procesne metode se zasnivaju na preduzeću ili specifičnim informacijama procesa. Uticaji se obično izračunavaju tokom čitavog životnog ciklusa proizvoda, povezivanjem uticaja radne sredine sa funkcionalnom jedinicom [1].

Kako bi se pomoglo u definisanju vrednosti funkcionalne jedinice, predloženo je pet koraka:
1. opisati proizvod prema njegovim osobinama, uključujući društvenu korisnost proizvoda;

2. odrediti odgovarajući tržišni segment;

3. utvrditi relevantne alternative proizvoda;

4. definisati i kvantifikovati funkcionalnu jedinicu, $u$ smislu obaveznih svojstava proizvoda koje zahteva relevantni segment tržišta, $\mathrm{i}$

5. odrediti referentni tok za svaki od proizvodnih sistema [3].

Aspekti radne sredine biće sve više integrisani u LCA praksi i smernice za S-LCA će jasno postaviti faze koraka za ocenjivanje uticaja radne sredine. U narednom poglavlju dat je primer primene WE-LCA metode prilikom ocenjivanja uticaja proizvodnje mikrotalasne pećnice.

\section{PRIMENA WE-LCA METODE ZA ANALIZU MIKROTALASNE PEĆNICE}

Evropsko tržište pokazuje trend kupovine jeftinih konvencionalnih mikrotalasnih pećnica, snage $1150 \mathrm{~W}$, kapaciteta od oko 18 litara, a od kojih je većina proizvodena u Jugoistočnoj Aziji. U skladu sa uočenom tendencijom tržišta, izabrana je mikrotalasna pećnica koja se proizvodi u Kini, snage 1150 W i kapaciteta 17 litara. Glavni ciljevi istraživanja su ocenjivanje uticaja životnog ciklusa mikrotalasne pećnice na radnu sredinu čoveka $\mathrm{i}$ identifikovanje faza životnog ciklusa koje najviše doprinose uticaju (engl. "hotspots").

\subsection{Funkcionalna jedinica i granice sistema}

Kao deo područja primene potrebno je definisati funkciju i funkcionalnu jedinicu proizvoda. Funkcionalna jedinica je jedna mikrotalasna pećnica koja ima upotrebni životni ciklus od osam godina. Granice sistema prikazane su na sl. 1 i odnose se na određivanje jediničnih procesa koje treba uključiti u sistem koji se ocenjuje.

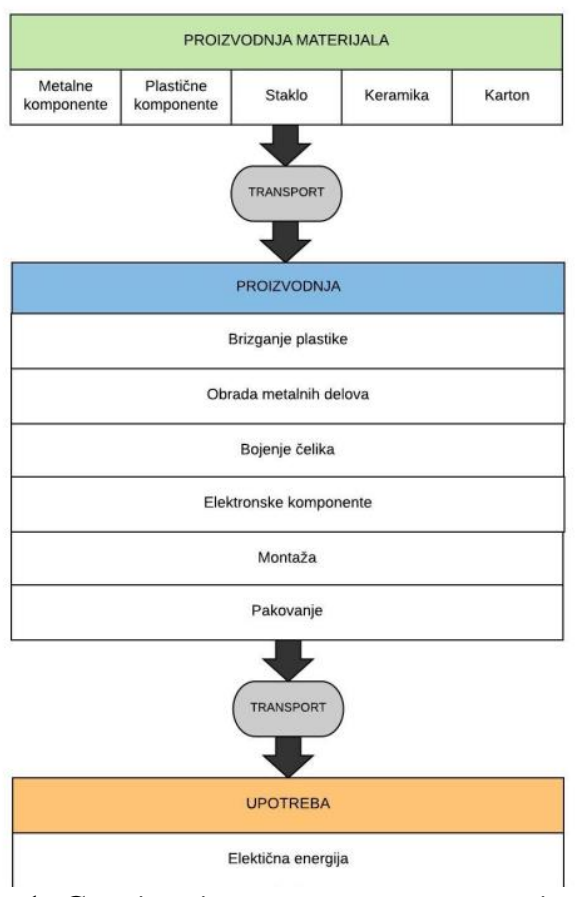

Slika 1. Granice sistema posmatranog proizvoda 
Sa slike 1 možemo uočiti da je proizvodni sistem napravljen od lančanih procesa, od resursa do faze upotrebe. Sistem takođe sadrži energiju i pomoćne ulazne tokove, kao što je transport, koji podržavaju glavnu proizvodnju, i proizvodnju svih pojedinačnih proizvodnih procesa. Nakon određivanja granica sistema, odlučuje se o potrebnim podacima, što je objašnjeno u narednom poglavlju.

\subsection{Prikupljanje podataka}

Primarni podaci određeni su merenjem sastavnih delova mikrotalasne pećnice koja je prikazana na sl. 2. Na osnovu primarnih podataka došlo se do detaljnijeg opisa proizvodnih procesa, upotrebom baze podataka. Količine i vrste materijala za proizvodnju mikrotalasnih pećnica i pakovanja, dobijeni su iz specifikacija glavnog distributera.

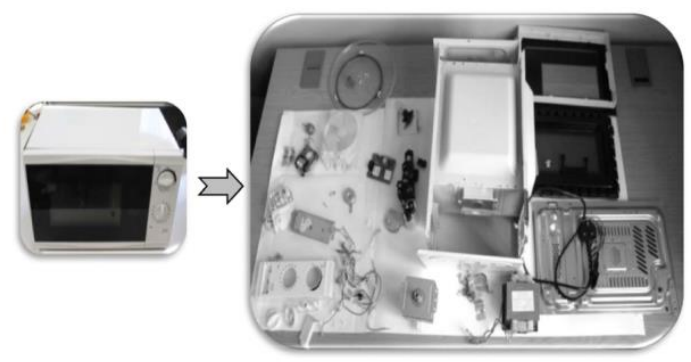

Slika 2. Mikrotalasna pećnica i njeni sastavni delovi [4]

Sa sl 2. možemo uočiti da je mikrotalasna pećnica, između ostalog, sastavljena od metalnih komponenti, čija je ukupna količina $8,6 \mathrm{~kg}$. Metalni delovi izrađeni su od: pocinkovanog čelika (kućište, transformator, magnetron i vijci), bakra (utičnica, kabl za napajanje, žice kablova, magnetron, transformator, kondenzator), mesinga (utičnica), aluminijuma (magnetron, transformator, kondenzator), gvožđa (magneti u magnetronu) i male količine kalaja, olova, zlata, nikla, srebra, cinka i platine. U tabeli 1 prikazane su metalne komponente, njihove količine $\mathrm{i}$ šifre $\mathrm{u}$ bazi.

Tabela 1. Podaci inventara za proizvodnju metalnih komponenti mikrotalasne pećnice [4]

\begin{tabular}{|c|c|c|c|}
\hline \multicolumn{4}{|c|}{ Proizvodnja metalnih komponenti } \\
\hline Materijal & Količina & $\begin{array}{c}\text { Proces iz baze } \\
\text { podataka }\end{array}$ & $\begin{array}{l}\text { Primenjena } \\
\text { količina }\end{array}$ \\
\hline $\begin{array}{l}\text { Pocinkovani } \\
\text { čelik }\end{array}$ & $7040 \mathrm{~g}$ & $\begin{array}{c}271000 \\
\text { Proizvodnja čelika }\end{array}$ & $7040 \mathrm{~g}$ \\
\hline Bakar & $645 \mathrm{~g}$ & $\begin{array}{c}274400 \\
\begin{array}{c}\text { Proizvodnja bakra } \\
\text { (Danska) }\end{array}\end{array}$ & $645 \mathrm{~g}$ \\
\hline Aluminijum & $618 \mathrm{~g}$ & $\begin{array}{c}274200 \\
\text { Proizvodnja aluminijuma }\end{array}$ & $618 \mathrm{~g}$ \\
\hline Gvožđe & $280 \mathrm{~g}$ & $\begin{array}{c}271000 \\
\text { Proizvodnja čelika }\end{array}$ & $280 \mathrm{~g}$ \\
\hline Mesing & $20 \mathrm{~g}$ & Nije dostupno & 1 \\
\hline Kalaj & $1,8 \mathrm{~g}$ & $\begin{array}{c}274300 \\
\text { Proizvodnja kalaja, } \\
\text { cinka i olova }\end{array}$ & $1,8 \mathrm{~g}$ \\
\hline Olovo & $1,2 \mathrm{~g}$ & $\begin{array}{c}274300 \\
\begin{array}{c}\text { Proizvodnja kalaja, } \\
\text { cinka i olova }\end{array} \\
\end{array}$ & $1,2 \mathrm{~g}$ \\
\hline Cink & $0,6 \mathrm{~g}$ & $\begin{array}{c}274300 \\
\text { Proizvodnja kalaja, } \\
\text { cinka i olova }\end{array}$ & $0,6 \mathrm{~g}$ \\
\hline Zlato & $0,015 \mathrm{~g}$ & Zlato & $0,015 \mathrm{~g}$ \\
\hline Srebro & $0,06 \mathrm{~g}$ & Nije dostupno & 1 \\
\hline Nikl & $0,6 \mathrm{~g}$ & Nikl & $0,6 \mathrm{~g}$ \\
\hline
\end{tabular}

U nastavku rada, na osnovu nabrojanih metalnih komponenti, primenom baze podataka predstavljeni su dobijeni rezultati za referentnu mikrotalasnu pećnicu sa aspekta bezbednosti i zdravlja na radu, ocenjeni u skladu sa WELCA smernicama.

\section{REZULTATI I DISKUSIJA}

Prvi korak interpretacije rezultata imao je za cilj da prikaže faze životnog ciklusa mikrotalasne pećnice koje najviše doprinose povredama i oboljenjima. Slika 3 prikazuje objedinjene uticaje proizvodnje mikrotalasne pećnice na bezbednost i zdravlje radnika sa razmatranim fazama životnog ciklusa.

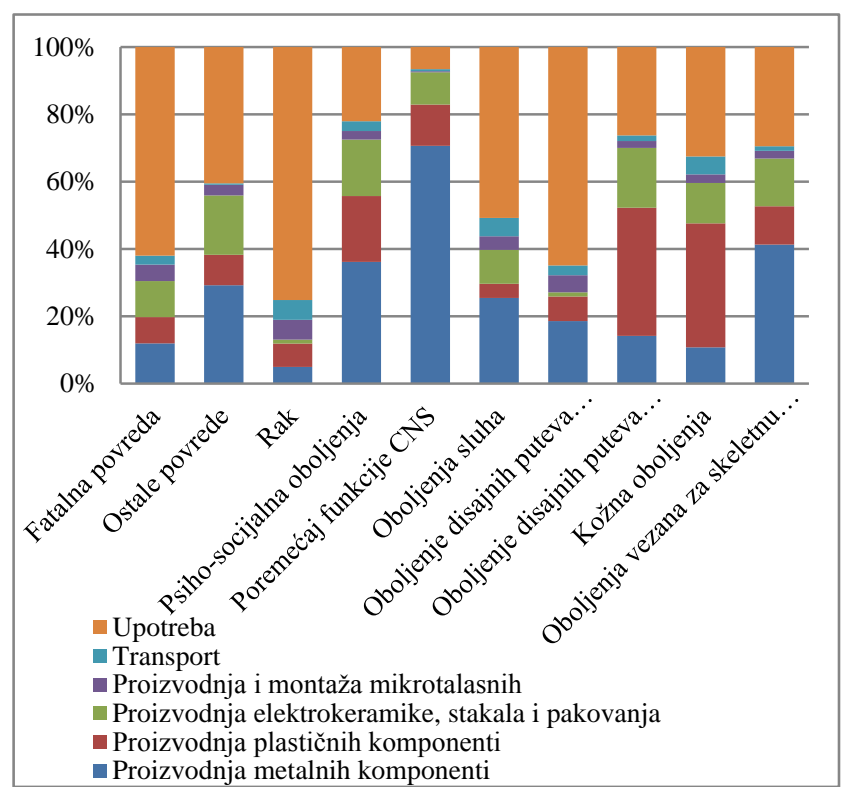

\section{Slika 3. Objedinjeni uticaj proizvodnih procesa na} bezbednost $i$ zdravlje radnika

Na sl. 3 se može uočiti da je faza upotrebe na prvom mestu, a razlog tome su brojne opasnosti prilikom proizvodnje električne energije, koja je potrebna za rad uređaja. Nakon faze upotrebe, proizvodnja metalnih komponenti ima najveći uticaj za sve definisane kategorije povreda i oboljenja. Većina ovih uticaja potiče od procesa proizvodnje bakra i pocinkovanog čelika koji se koriste $\mathrm{u}$ električnim kablovima i elektronskim delovima. Nastavak istraživačkog dela rada obuhvatio je rezultate koji se odnose na posmatranje pojedinačnih materijala i procesa.

\subsection{Uticaj proizvodnje metalnih komponenti}

U prethodnom poglavlju je navedeno da faza proizvodnje metalnih komponenti ima znatnog uticaja na sve kategorije definisanih povreda i oboljenja. Informacije iz baze podataka dobijene su pomoću statistika koje se odnose na izveštavanje $u$ vezi sa oboljenjima i povredama na radu $u$ Danskoj.

$\mathrm{Na}$ sl. 4. se može primetiti da je dominantan uticaj pocinkovanog čelika, kao i da je u najvećoj meri povezan sa poremećajima funkcije CNS-a.

U obzir treba uzeti i uticaje aluminijuma jer usled inhalacije čistog aluminijumovog praha ili gasova njegovih oksida može doći do fibroze pluća - aluminoze [5]. 


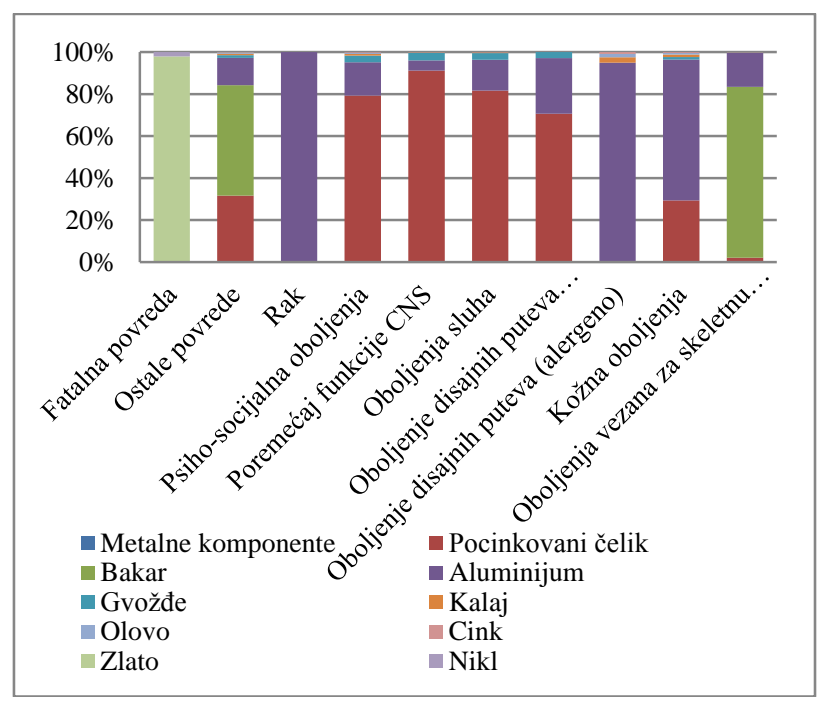

Slika 4. Uticaj proizvodnje metalnih komponenti

\subsection{Normalizacija uticaja}

Kada se izvodi korak normalizacije koristi se ekvivalent po osobi opšte populacije i ekvivalent po osobi profesionalne izloženosti. Cilj normalizacije jeste da pruži ukupan pregled relativne značajnosti jedne kategorije uticaja. Normalizacija je urađena povezivanjem aktuelnog uticaja sa prosekom uticaja koju stvara osoba na određenom geografskom području.

Prilikom normalizacije, koristi se ukupan broj prijavljenih povreda i oboljenja na radnom mestu u Danskoj nacionalnoj inspekciji rada. Ukupan broj evidentiranih povreda i oboljenja deli se sa brojem stanovnika Danske. $\mathrm{Na}$ sledećoj sl. 5 prikazana je normalizacija uticaja proizvodnje mikrotalasne pećnice.

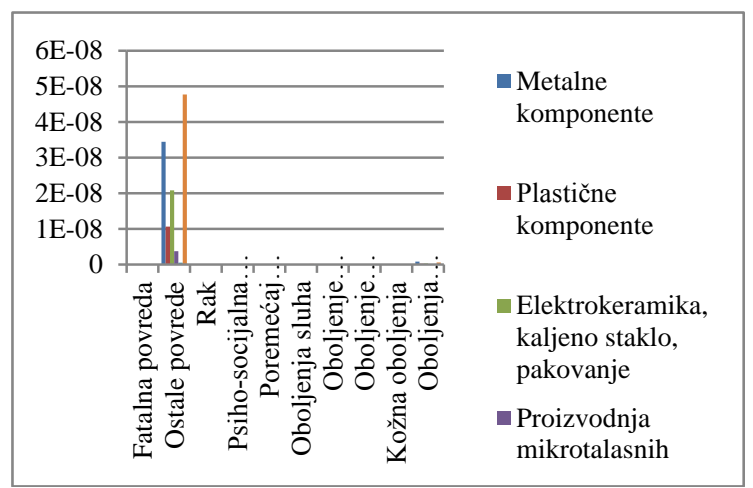

Slika 5. Normalizacija uticaja proizvodnje

Sa slike 5 se može videti da će najveći broj povreda i oboljenja na radu zadobiti zaposleni u fazi upotrebe, za koju je potrebno proizvesti električnu energiju. Nakon upotrebe, sledi proizvodnja metalnih komponenti. Na ovaj način potvrđeni su prethodno dobijeni rezultati.

\section{ZAKLJUČAK}

Detaljnim analizama, koje bi bile sprovedene u oblasti društveno odgovornog poslovanja, bilo bi moguće dobiti preciznije smernice za društveno prihvatljive metode proizvodnje, kao što je S-LCA.

Prilikom korišćenja S-LCA, treba se fokusirati na faze životnog ciklusa u kojima su potrebna poboljšanja.
Poređenjem klasične LCA i WE-LCA može se zaključiti da je značajnost obe metode velika, obzirom na to da proizvodni procesi mogu da utiču negativno i na životnu sredinu i na radnika. Metoda WE-LCA slična je proceni rizika radnog mesta. Analiziranjem dobijenih rezultata došlo se do zaključka da primena metode WE-LCA doprinosi da se broj radnih povreda u radnom okruženju smanji, tj. omogućuje preventivno izračunavanje uticaja na radnu sredinu čime se osigurava da radni procesi budu bezbedniji i manje štetni.

Rezultati ocenjivanja uticaja životnog ciklusa mikrotalasne pećnice, koji su predstavljeni u radu, pokazuju da faza upotrebe, za koju je potrebna električna energija, najviše doprinosi uticaju na radnike. Takođe, proizvodnja metalnih komponenti ima određen uticaj za svih deset definisanih kategorija uticaja, posebno za poremećaj funkcije centralnog nervnog sistema. Stručne smernice mogu pomoći kompanijama da prilikom ocenjivanja životnog ciklusa proizvoda integrišu radnu sredinu u svoju svakodnevnu praksu i na taj način odgovore na pitanja društvene odgovornosti.

\section{LITERATURA}

[1] Andrews E. S, Barehel L. P, Beck T, Benoit C, Ciroth A, Cucuzella C,Gensch C. O, Hérbert J, Lesage P, Manhart A, Mazeau P, Mazijn B, Methot A. L, Moberg A, Norris G, Parent J, Prakash S, Reveret J. P, Spillemaeckers S, Ugaya C. M. L, Valdivis S, Weidema B. 2009. UNEP/SETAC Life Cycle Initiative: Guidelines for social life cycle assessment of products, Belgium Federal Public Planning Service Sustainable Development.

[2] Schmidt A, Poulsen B. P, Andreasen J, FlØe T, Poulsen E. K. 2004. The working environment in LCA. A new approach, MiljØstzrelsen, Danska.

[3] Weidema B, Cappellaro F, Carlson R, Notten P, Pålsson A. C, Patyk A, Regalini E, Sacchetto F, Scalbi S. 2004.

Procedural Guideline for Collection, Treatment and Quality Documentation of LCA Data. 2.-0 LCA Consultants, Denmark.

[4] Gallego-Schmid, A., Mendoza J., Azapagic A., 2018. Environmental assessment of microwaves and the effect of European energy efficiency and waste management legislation. Science of The Total Environment 618 (3): 487 499.

[5] Aranđelović M., Jovanović J., 2009. Medicina rada: Prvo elektronsko izdanje za studente integrisanih akademskih i osnovnih strukovnih studija. Medicinski fakultet, Univerzitet u Nišu.

\section{Kratka biografija:}

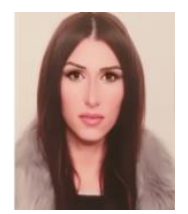

Marina Jakovljević rođena je u Kruševcu 1991. godine. Master rad na Fakultetu tehničkih nauka iz oblasti Inženjerstva zaštite na radu odbranila je 2019. god.

kontakt: marina.ac@hotmail.it

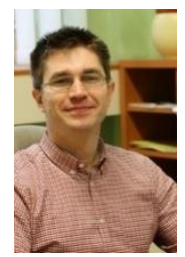

Boris Agarski rođen je u Novom Sadu 1980. godine. Doktorirao je na Fakultetu tehničkih nauka 2015. godine, a od 2016. je u zvanju docent. Oblast interesovanja su inženjerstvo zaštite životne sredine, višekriterijumska analiza i ocenjivanje životnog ciklusa proizvoda i procesa. 